BMC

Microbiology

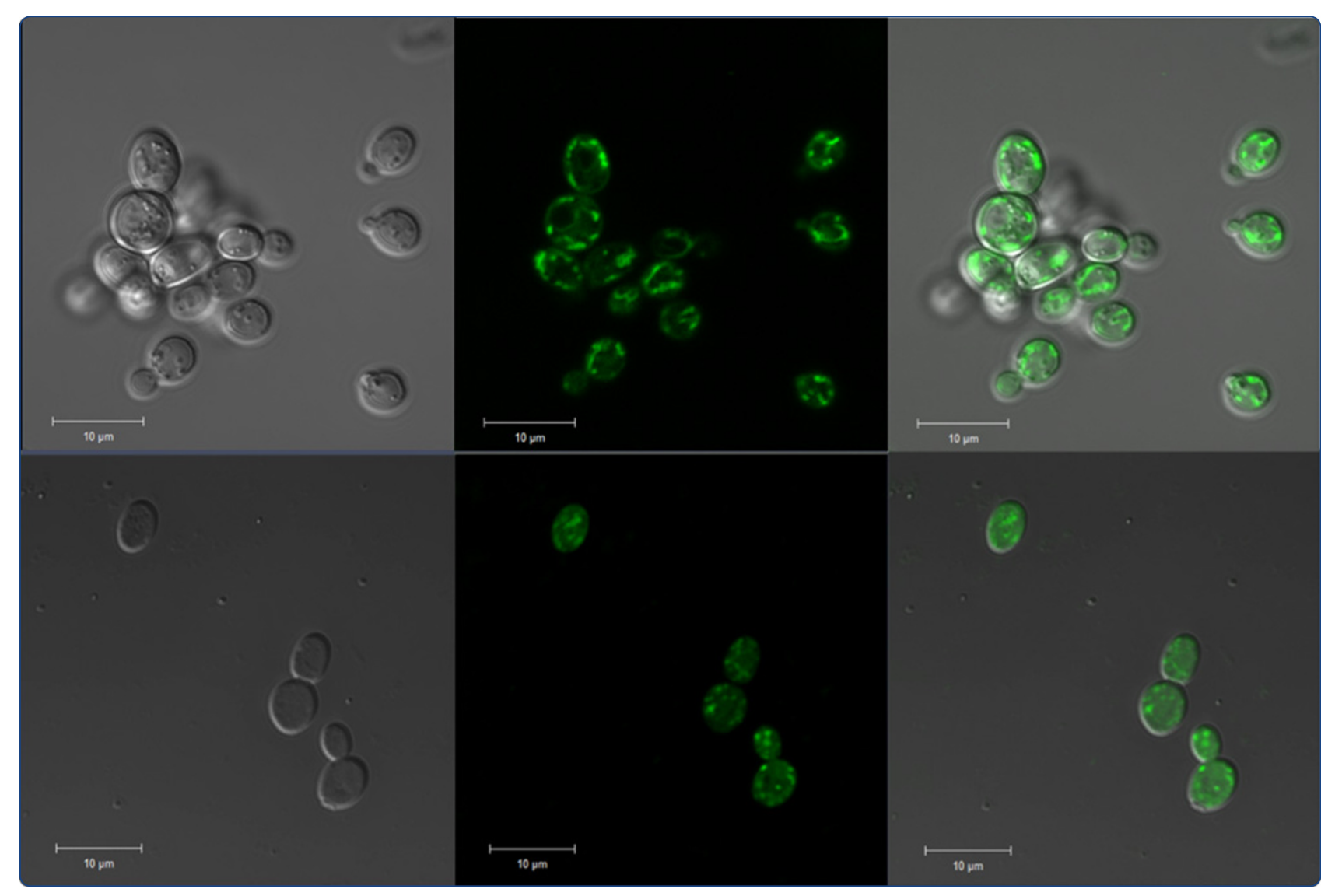

S-Adenosyl-L-Methionine protects the probiotic yeast, Saccharomyces boulardii, from acid-induced cell death

Cascio et al.

() Biomed Central 


\title{
S-Adenosyl-L-Methionine protects the probiotic yeast, Saccharomyces boulardii, from acid-induced cell death
}

Vincent Cascio ${ }^{1,2}$, Daniel Gittings ${ }^{1,3}$, Kristen Merloni $^{1}$, Matthew Hurton ${ }^{1}$, David Laprade ${ }^{1,4}$ and Nicanor Austriaco OP ${ }^{1^{*}}$

\begin{abstract}
Background: Saccharomyces boulardii is a probiotic yeast routinely used to prevent and to treat gastrointestinal disorders, including the antibiotic-associated diarrhea caused by Clostridium difficile infections. However, only 1-3\% of the yeast administered orally is recovered alive in the feces suggesting that this yeast is unable to survive the acidic environment of the gastrointestinal tract.
\end{abstract}

Results: We provide evidence that suggests that $S$. boulardii undergoes programmed cell death (PCD) in acidic environments, which is accompanied by the generation of reactive oxygen species and the appearance of caspaselike activity. To better understand the mechanism of cell death at the molecular level, we generated microarray gene expression profiles of S. boulardii cells cultured in an acidic environment. Significantly, functional annotation revealed that the up-regulated genes were significantly over-represented in cell death pathways Finally, we show that S-adenosyl-L-methionine (AdoMet), a commercially available, FDA-approved dietary supplement, enhances the viability of $S$. boulardii in acidic environments, most likely by preventing programmed cell death.

Conclusions: In toto, given the observation that many of the proven health benefits of S. boulardii are dependent on cell viability, our data suggests that taking S. boulardii and AdoMet together may be a more effective treatment for gastrointestinal disorders than taking the probiotic yeast alone.

Keywords: S-Adenosyl-L-Methionine, Saccharomyces boulardii, Probiotic, Acid-induced cell death

\section{Background}

Saccharomyces boulardii is a non-pathogenic yeast classified as a probiotic - a live microorganism which, when administered in adequate amounts, confers a health benefit on the host - by the World Health Organization [1]. Available for sale in over 100 countries under the brand name Florastor, this yeast has been prescribed for over fifty years to help maintain the natural flora of the gastrointestinal tract $[2,3]$. Florastor is also sold as an alternative remedy for acute childhood diarrhea [4] and traveller's diarrhea [5]. Clinically, S. boulardii has been prescribed to treat antibiotic-associated diarrhea (AAD) linked to bacterial infections, especially the AAD associated with Clostridium difficile, the cause of about a third of all

\footnotetext{
*Correspondence: naustria@providence.edu

'Department of Biology, Providence College, 1 Cunningham Square, Providence, Rhode Island 02918, USA

Full list of author information is available at the end of the article
}

AAD cases [6-11]. Significantly, the effectiveness of $S$. boulardii as a probiotic has been demonstrated in numerous clinical trials in both pediatric and adult patient populations [9,12-15].

Studies have shown that the therapeutic effect of Saccharomyces boulardii can be attributed to the organism's ability to interfere with and to destroy pathogenic toxins, to decrease bacterial adhesion to intestinal epithelial cells, to preserve the cellular integrity of the intestinal lining, and to restore the intestinal microbiome when it is destroyed [12,16,17]. S. boulardii is also able to modify the host's immune response by either acting as an immune stimulant or by reducing pro-inflammatory responses [18].

Although several studies had suggested that $S$. boulardii is indistinguishable from other strains of Saccharomyces cerevisiae, the common baker's yeast used in laboratories worldwide $[3,19,20]$, more recent work has shown that $S$. boulardii has unique genetic, physiological, and metabolic 
properties that can be used to differentiate it as a subspecies from S. cerevisiae [21,22]. For example, S. boulardii grows best at $37^{\circ} \mathrm{C}$ and is able to tolerate low $\mathrm{pH}$, while $S$. cerevisiae prefers cooler temperatures around $30^{\circ} \mathrm{C}$ and cannot survive acidic environments [22,23]. These phenotypic differences could explain both why $S$. boulardii can persist in the gnotobiotic mouse models (10d) while $S$. cerevisiae cannot $(<1 \mathrm{~d})$ [24,25]. Furthermore, the phenotypic differences may also explain why $S$. boulardii can act as a probiotic, while $S$. cerevisiae cannot.

In order to benefit the host, probiotics given orally must not only survive the initial transit through the stomach, but also must be able to persist in the intestine [26]. Studies have reported that only between $1-3 \%$ of live yeast is recovered in human feces after oral administration $[27,28]$, as the acidic conditions disrupt cell wall function and cause morphological alterations, leading to cell death $[27,29]$. However, the nature of this cell death remains unclear.

Recent studies with Saccharomyces cerevisiae have shown that this budding yeast is able to undergo programmed cell death (PCD) that is associated with characteristic cell markers reminiscent of apoptosis in mammalian cells including the accumulation of reactive oxygen species (ROS), the condensation of chromatin, the fragmentation of the nucleus, the degradation of DNA, and the activation of caspase-like enzymatic activities [30]. Numerous external stimuli can induce PCD in yeast including hydrogen peroxide, acetic acid, ethanol, high salt, UV irradiation, and heat stress, among others [31-33]. Significantly, one study has shown that $S$. cerevisiae cells undergo apoptotic cell death in acidic environments [34]. PCD has also been linked to intrinsic processes including colony differentiation, replicative and chronological aging, and failed mating events [35-39]. Finally, the process of yeast programmed cell death is mediated by genes that have orthologs that have been implicated in mammalian apoptosis [40].

In this paper we provide evidence that suggests that Saccharomyces boulardii, when cultured in either ethanol, acetic acid, or hydrocholoric acid, dies with the fragmentation of mitochondria, the production of reactive oxygen species, and the activation of caspase-like enzymatic activity, three hallmarks of PCD in Saccharomyces cerevisiae. Moreover, we show that S-adenosyl-L-methionine (AdoMet), a commercially available dietary supplement, enhances the viability of $S$. boulardii in acidic environments, most likely by preventing programmed cell death. In toto, given the observation that many of the proven health benefits of $S$. boulardii are dependent on cell viability, our data suggests that taking $S$. boulardii and AdoMet together may be a more effective treatment for gastrointestinal disorders than taking the probiotic yeast alone.

\section{Methods}

Yeast strains, plasmids, and growth conditions

All experiments were done with isogenic Sacharomyces cerevisiae strains in the W303-1B background (MAT $\alpha$ ade2, his3, leu2, trp1, ura3, ssd1-d2), and with Saccharomyces boulardii (Florastor, Lot No. 538) obtained from Biocodex, Inc. (San Bruno, CA). For all the experiments described in this paper, cells were cultured and treated using standard yeast protocols [41]. Unless noted otherwise, all other drugs and reagents were purchased from SIGMA-Aldrich.

\section{Ethanol-induced cell death assay}

Cells of the indicated strain and genotype were cultured in rich YPD media overnight, resuspended in fresh media, and allowed to reach exponential phase (an approximate $\mathrm{OD}_{600}$ value of 0.2 ). They were then resuspended in water or fresh media or in water or fresh media containing either $15 \%$ or $22 \%$ ethanol [33], and allowed to grow at $30^{\circ} \mathrm{C}$ for the indicated times. Next, they were either serially diluted onto YPD plates and cultured at $30^{\circ} \mathrm{C}$ for 2 days to test for viability or treated with the appropriate stain for the indicated test, and examined using a Zeiss LSM 700 Confocal Laser Scanning Microscope. At least three independent cultures were tested and compared. Statistical significance was determined with the Student's t-test.

\section{Acetic acid-induced cell death assay}

Cells of the indicated genotype were cultured in rich YPD media overnight, resuspended in fresh media, and allowed to reach exponential phase (an approximate $\mathrm{OD}_{600}$ value of 0.2 ). They were then resuspended in fresh media $\mathrm{pH} 3$ or fresh media $\mathrm{pH} 3$ containing $160 \mathrm{mM}$ acetic acid, allowed to grow at $30^{\circ} \mathrm{C}$ with shaking for 2 hours. Next, they were treated with the appropriate stain for the indicated test, and examined using a Zeiss LSM 700 Confocal Laser Scanning Microscope.

\section{Hydrochloric acid-induced cell death assay}

Cells of the indicated genotype were cultured in rich YPD media overnight, resuspended in fresh media, and allowed to reach exponential phase (an approximate $\mathrm{OD}_{600}$ value of 0.2 ). They were then resuspended in water, water containing either $50 \mathrm{mM}$ or $75 \mathrm{mM} \mathrm{HCl}$, water containing $50 \mathrm{mM} \mathrm{HCl}$ and $2 \mathrm{mM}$ AdoMet, or water containing $2 \mathrm{mM}$ AdoMet alone. They were allowed to sit at room temperature for 1.5 hours. Then, they were either serially diluted onto YPD plates and cultured at $30^{\circ} \mathrm{C}$ for 2 days to test for viability or treated with the appropriate stain for the indicated test, and examined using a Zeiss LSM 700 Confocal Laser Scanning Microscope. 


\section{Viability assay}

Cells were grown overnight in rich YPD media at $30^{\circ} \mathrm{C}$ and then diluted to a final concentration (an approximate $\mathrm{OD}_{600}$ value of 0.2 ). For each strain, a series of 10 -fold dilutions was then prepared in water over a range of concentrations from $10^{-1}$ to $10^{-5}$ relative to the initial culture. Spots of $5 \mu \mathrm{l}$ from each dilution series were then plated on the indicated media and cultured at $30^{\circ} \mathrm{C}$ for 2 days. Individual colonies were then counted and compared to the number of colonies observed from an untreated culture serially diluted at the beginning of the experiment. Several serial dilutions for each culture were done to ensure that there were enough colonies to count for statistical significance and at least three independent cultures were tested and compared. Statistical significance was determined with the Student's t-test. Note that after $3 \mathrm{hr}$, cells cultured in rich media without any cell death inducing agents were able to grow and to divide, hence the relative viability levels that are greater than $100 \%$.

\section{In vivo detection of mitochondrial fragmentation, ROS accumulation, and caspase activation}

Mitochondrial fragmentation was detected in S. boulardii cells using $10 \mathrm{nM}$ Mitotracker Green (Molecular Probes), according to the manufacturer's specifications. Intracellular ROS accumulation was examined after treatment with $5 \mu \mathrm{g} / \mathrm{ml}$ of dihydrorhodamine 123 (DHR123; Sigma Aldrich) [42]. Activated caspase-like activity was detected in $S$. boulardii cells after treatment using a FLICA apoptosis detection kit (ImmunoChemistry Technologies, LLC) according to the manufacturer's specifications $[43,44]$. After exposure to reagents, $S$. boulardii cells were harvested and examined using a Zeiss LSM 700 Confocal Laser Scanning Microscope.

\section{Fluorescence microscopy}

Cells were grown to mid-log phase in selective media and examined using a 63X oil-immersion objective and a pinhole size of 1 Airy Unit using a Zeiss LSM 700 Laser Confocal Microscope Images were captured and processed using the ZEN 2009 software package.

\section{Microarray experiments: array design}

Genomic sequences were obtained from the Saccharomyces Genome Database (downloaded from www.yeastgenome. org). These sequences were used to design a custom $8 \times 15 \mathrm{~K}$ array using the Agilent eArray software (http://earray. chem.agilent.com/). Each array had a minimum of 2 unique 60-mer probes designed against 6,612 open reading frames encoded by $S$. cerevisiae. This resulted in a total of 13,275 unique probes for each array, including Agilent hybridization controls.

\section{Microarray experiments: sample preparation, extraction, and purification}

$S$. boulardii cells were cultured in rich YPD media overnight, resuspended in fresh media, and allowed to reach exponential phase (an approximate $\mathrm{OD}_{600}$ value of 0.2 ). They were then resuspended in $45 \mathrm{~mL}$ of either water, for the control condition, or water containing $50 \mathrm{mM}$ $\mathrm{HCl}$ for the experimental condition. The total number of cells in each experiment was $3 \times 10^{8}$, as measured with a spectrophotometer. After a $1.5 \mathrm{hr}$ incubation with shaking at room temperature, the cells were washed with $1 \mathrm{x}$

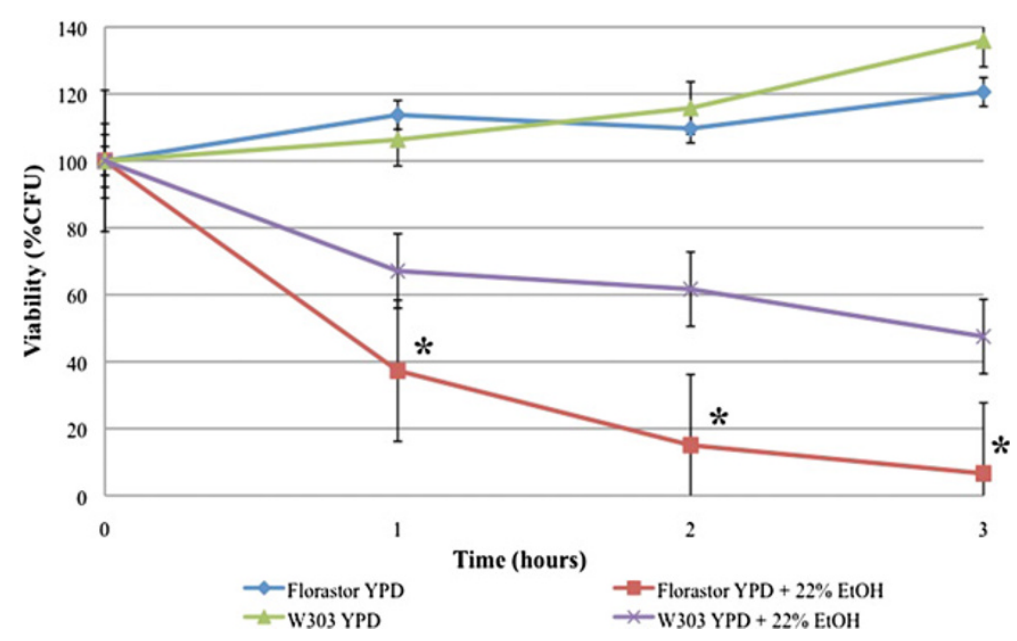

Figure 1 S. boulardii has decreased viability in ethanol, similar to S. cerevisiae. S. boulardii (Florastor) and S. cerevisiae (W303a) were cultured in rich YPD media overnight and resuspended in fresh media and allowed to reach exponential phase. They were then resuspended in fresh media or in fresh media containing $22 \%$ ethanol, allowed to grow at $30^{\circ} \mathrm{C}$ for the indicated times, serially diluted onto YPD plates, and cultured at $30^{\circ} \mathrm{C}$ for 2 days. Viability was measured as percentage colony forming units. At least three independent cultures were tested and compared. Note that after 3 hr, cells cultured in rich media without any cell death inducing agents were able to grow and to divide, hence the relative viability levels that are greater than $100 \%$. The differences in viabilities were deemed statistically significant by the Student's t-test $(p<0.05)$. 


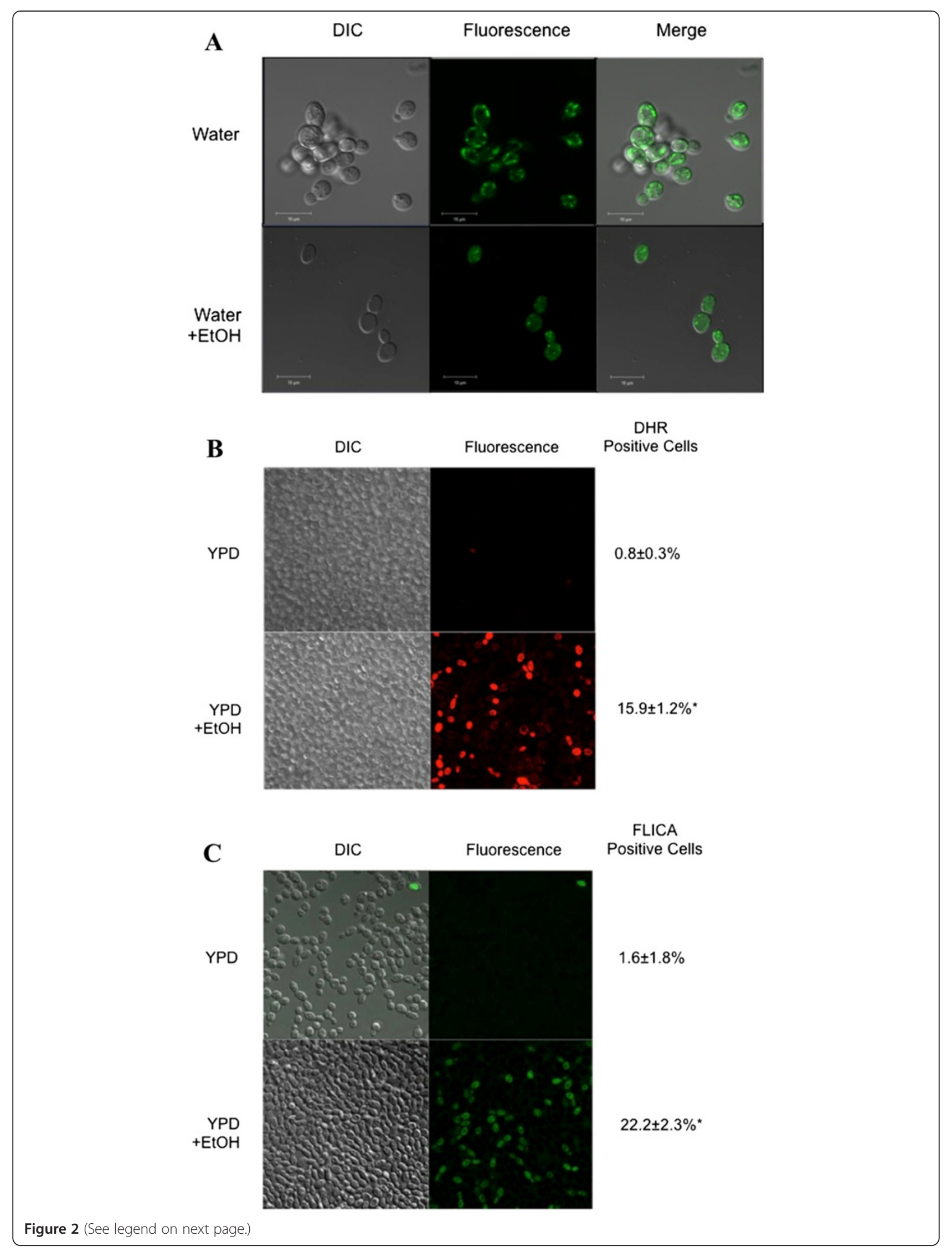


(See figure on previous page.)

Figure 2 Like S. cerevisiae, S. boulardii cells undergo programmed cell death in ethanol. S. Boulardii cells were cultured in rich YPD media overnight and resuspended in fresh media and allowed to reach exponential phase. They were then resuspended either in water or fresh media or in water or fresh media containing either $15 \%$ or $22 \%$ ethanol, and allowed to grow at $30^{\circ} \mathrm{C}$ for the indicated times. (A) Mitochondrial fragmentation was detected in cells cultured in 15\% ethanol using $10 \mathrm{nM}$ Mitotracker Green. (B) Intracellular ROS accumulation was detected in cells cultured in $22 \%$ ethanol with $5 \mathrm{\mu g} / \mathrm{ml}$ of dihydrorhodamine 123. (C) Activated caspase-like enzymatic activity was detected in S. boulardii cells cultured in $22 \%$ ethanol using a FLICA apoptosis detection kit according to the manufacturer's specifications. At least three independent cultures were tested and compared. The differences in staining patterns were deemed statistically significant by the Student's t-test ( $p<0.05)$.

PBS, frozen in liquid nitrogen, and stored at $-80^{\circ} \mathrm{C}$. Total RNA was then extracted using a RiboPure Yeast Kit (Ambion) and purified of gDNA with Turbo DNase (Ambion). RNA was assessed using a NanoDrop-2000c spectrophotometer (Thermo Scientific) and Agilent 2100 bioanalyzer to determine RNA concentration, purity, and integrity.

\section{Microarray experiments: cDNA synthesis, labeling, and hybridization}

cDNA was generated from $10 \mu \mathrm{g}$ aliquots of purified RNA by first annealing hand-mixed random oligonucleotides (pdN9, $6.3 \mu \mathrm{g})$ and oligo $(\mathrm{dT}){ }_{19} \mathrm{~V}(8.3 \mu \mathrm{g})$ obtained from IDT (Integrated DNA Technologies). First strand cDNA synthesis was then performing using Super Script III reverse transcriptase (Invitrogen) in a reaction containing $0.25 \mathrm{mM}$ DTT and $0.5 \mathrm{mM}$ total deoxynucleoside triphosphates (amino-allyl-dUTP and deoxynucleoside triphosphates) in a ratio of 3:2 aa-dUTP. After synthesis for $3 \mathrm{hr}$ at $42^{\circ} \mathrm{C}$, the cDNA was hydrolyzed with 0.3 $\mathrm{M} \mathrm{NaOH}$ and $0.03 \mathrm{M}$ EDTA. The reaction was then neutralized with $0.3 \mathrm{M} \mathrm{HCl}$ to $\mathrm{pH}$ 7.0. Following this,
cDNA was purified using a 25 ug capacity DNA Concentrator and Cleanup Kit (Zymo), dried using a Speed-vac, resuspended in $\mathrm{ddH}_{2} \mathrm{O}(2 \mu \mathrm{g}$ cDNA per $9 \mu \mathrm{l}$ water $)$, and stored at $-80^{\circ} \mathrm{C}$. Dye coupling was achieved by adding $1 \mu \mathrm{L}$ of 1.0 M NaHCO 3 solution ( $\mathrm{pH} 9.0)$ and $1.25 \mu \mathrm{L}$ of either Cy3 or Cy5 Amersham monoreative dye (GE Healthcare; dissolved in DMSO) to each $9 \mu \mathrm{L}$ aliquot of cDNA, then incubating for $1 \mathrm{hr}$ at room temperature in darkness. Unincorporated dye was removed and the samples purified using the Zymo cleanup kit. Dye incorporation and cDNA yield were quantified using the NanoDrop2000c spectrophotometer on the microarray setting. $300 \mathrm{ng}$ of the relevant Cy3- and Cy5-stained cDNAs (control and experiment) were then pooled in a total volume of $25 \mu \mathrm{L} d \mathrm{ddH}_{2} \mathrm{O}$ and denatured at $95^{\circ} \mathrm{C}$ for 3 min. Following denaturation, $25 \mu \mathrm{L}$ of $2 x$ HiRPM gene expression and hybridization buffer (Agilent) was added to each sample. These cDNA solutions were then applied to the microarray slide and incubated at $65^{\circ} \mathrm{C}$ for $\sim 17 \mathrm{hr}$ in a hybridization oven, as per the manufacturer's instructions. The slides were then sequentially washed in a row of Agilent Wash Buffer I,

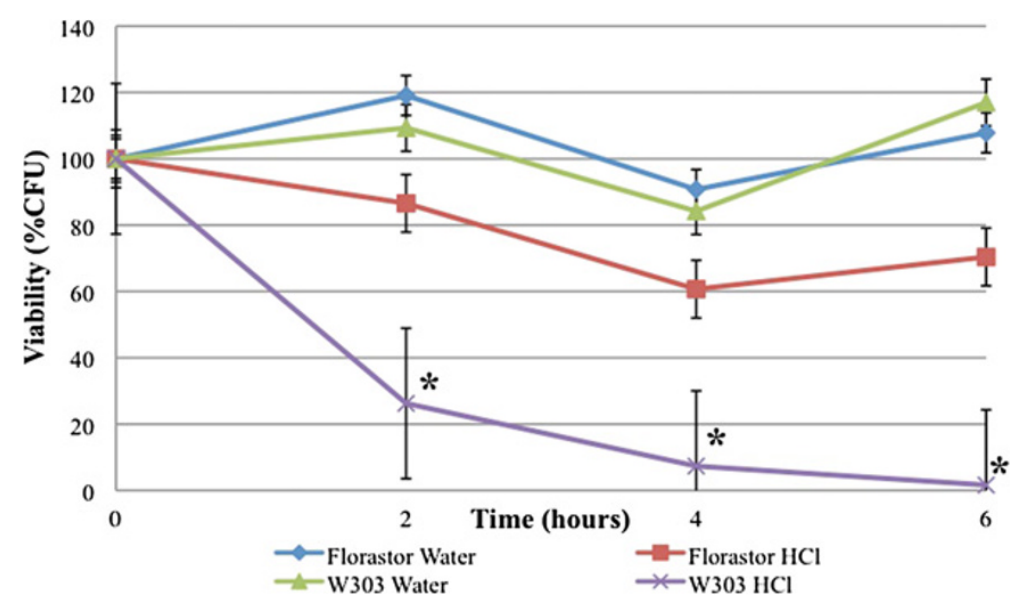

Figure 3 S. boulardii cells are more viable in $50 \mathrm{mM} \mathrm{HCl}$ than their S. cerevisiae counterparts. S. boulardii (Florastor) and S. cerevisiae (W303a) were cultured in rich YPD media overnight and resuspended in fresh media and allowed to reach exponential phase. They were then resuspended in water or water containing $50 \mathrm{mM} \mathrm{HCl}$ and allowed to grow at room temperature for the indicated times, serially diluted onto YPD plates, and cultured at $30^{\circ} \mathrm{C}$ for 2 days. At least three independent cultures were tested and compared. The differences in viabilities were deemed statistically significant by the Student's t-test $(p<0.05)$. 


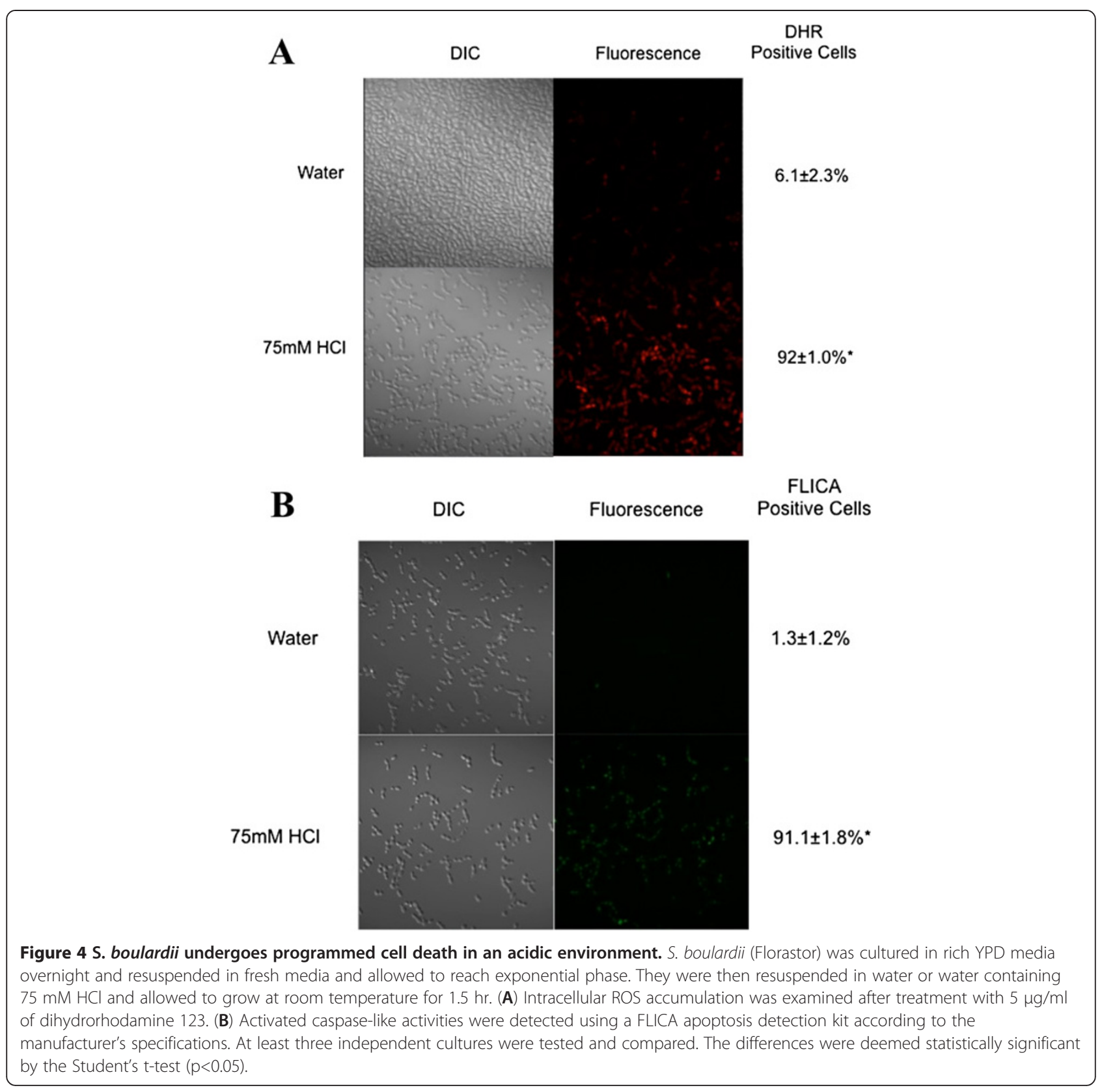

Agilent Wash Buffer II, and acetonitrile (Sigma), and dried using Agilent drying and stabilization buffer.

\section{Microarray data analysis and bioinformatics}

Slides were scanned using an Axon 4000B scanner (Molecular Devices) and fluorescence was quantified using GENE Pix Pro 3.0 software (Molecular Devices). Data was then normalized using the Goulphar transcriptome platform (http://transcriptome.ens.fr/goulphar/). Duplicate spots for each gene were averaged in Microsoft Excel, and the results were confirmed using qPCR. The Cytoscape 2.8.3 (http://www.cytoscape.org/ download.php) plugin BiNGO 2.44 was used to identify enriched biological processes in differentially expressed genes after Benjamini \& Hochberg false discovery correction for multiple hypothesis testing. Pairwise average linkage clustering analysis was performed using the program Cluster and visualized using Treeview [45].

\section{Results and Discussion}

Saccharomyces cerevisiae cells undergo programmed cell death when they are cultured in media containing either $15 \%$ or $22 \%$ ethanol [33]. To determine if S. boulardii also undergoes PCD, we began by comparing the viabilities of both these strains in ethanol. While the W303a strain shows almost $50 \%$ viability after three hours 


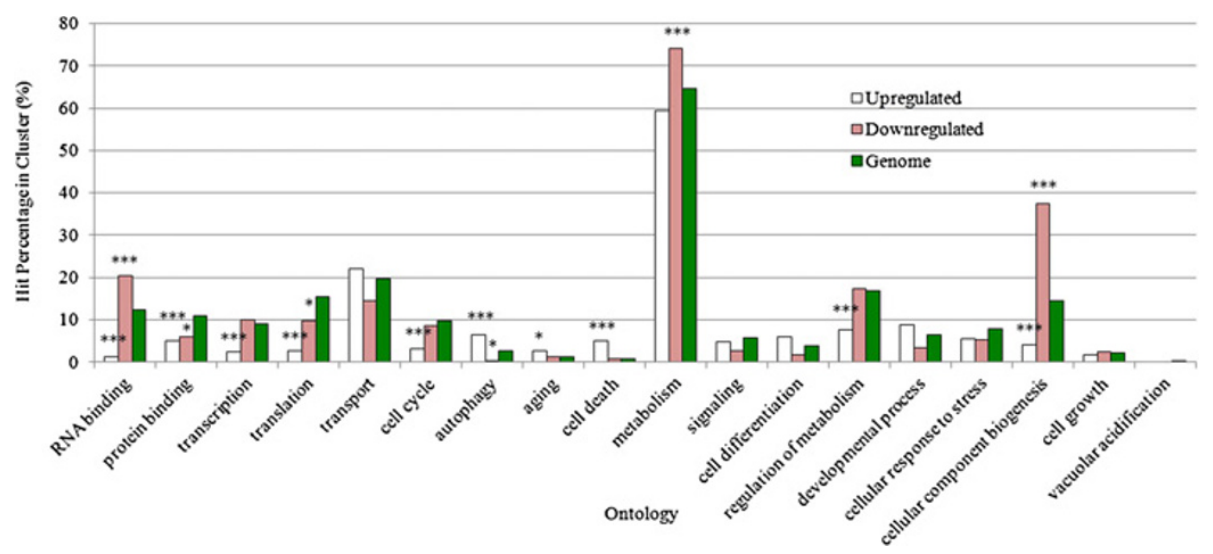

Figure 5 Functional classification/GO analysis of differentially transcribed genes in S. boulardii cells cultured in $50 \mathrm{mM} \mathrm{HCl}$. Genes showing 2-fold or greater increase (up-regulated) or decrease (down-regulated) in response to an acidic environment were grouped in functional categories. Categories that are significantly enriched relative to the yeast proteome are marked (*: $\left.p<0.05 ;{ }^{* * *}: p<0.0005\right)$.

suspended in $22 \%$ ethanol, S. boulardii shows less than $10 \%$ viability after growth in the same media (Figure 1 ). Our data suggests that $S$. boulardii is less viable in ethanol than this common laboratory strain of S. cerevisiae, which is not surprising given the adaptations of brewing yeast, $S$. cerevisiae, that allow it to undergo fermentation efficiently. (Note that after $3 \mathrm{hr}$, cells cultured in rich media without any cell death inducing agents were able to grow and to divide, hence the relative viability levels that are greater than 100\%).

Next, we examined the $S$. boulardii cells dying either in $15 \%$ or in $22 \%$ ethanol for markers indicative of PCD in yeast, including mitochondrial fragmentation, ROS accumulation, and caspase-like enzyme activation. As shown in Figure 2A, S. boulardii cells cultured in 15\% ethanol for $1.5 \mathrm{hr}$ had fragmented mitochondria - punctate fluorescence rather than the tubular fluorescence normally seen in wildtype yeast cells - as revealed by MitoTracker Green staining. Cells cultured in ethanol also accumulated ROS (Figure 2B) and manifested a caspase-like activity as measured by a FLICA assay (Figure 2C). Similar findings

Table 1 S. boulardii cell death genes differentially expressed in an acidic environment

\begin{tabular}{|c|c|c|c|c|}
\hline \multicolumn{5}{|c|}{ S. BOULARDII CELL DEATH GENES } \\
\hline \multicolumn{5}{|c|}{ DIFFERENTIALLY EXPRESSED IN AN ACIDIC ENVIRONMENT } \\
\hline \multicolumn{2}{|c|}{ MCD1 } & NMA111 & NUC1 & $\mathrm{TAH} 18$ \\
\hline ATP1 & ATP2 & ATP7 & COR1 & COX4 \\
\hline COX5A & COX6 & COX8 & CYT1 & INH1 \\
\hline OYE3 & PIN3 & POR1 & QCR2 & QCR6 \\
\hline QCR7 & QCR8 & QCR9 & QCR10 & RIP1 \\
\hline$R N Y 1$ & SDH1 & $\mathrm{SDH} 2$ & SDH4 & UBX6 \\
\hline
\end{tabular}

Saccharomyces boulardii cell death genes showing 2-fold or greater decrease (underlined) or increase (italics) in response to an acidic environment were identified using the Cytoscape 2.8.3 plugin BiNGO 2.44 after Benjamini \& Hochberg false discovery correction for multiple hypothesis testing. were obtained with S. boulardii cells cultured in $160 \mathrm{mM}$ acetic acid (data not shown), another known inducer of PCD in S. cerevisiae [46,47]. Together, these results suggest that Saccharomyces boulardii, like Saccharomyces cerevisiae, undergoes programmed cell death.

Studies have reported that only between $1-3 \%$ of live $S$. boulardii yeast is recovered in human feces after oral administration $[27,28]$ as the acidic conditions disrupt cell wall function and cause morphological alterations that lead to cell death $[27,29]$. However, the nature of this cell death in acidic environments remains unclear.

To determine the type of cell death experienced by $S$. boulardii cells in an acidic environment, we began by determining the viability of $S$. boulardii in low $\mathrm{pH}$ conditions. Our results show that $S$. boulardii cells have an increased viability in acidic conditions as compared to their $S$. cerevisiae counterpart. After six hours in $50 \mathrm{mM} \mathrm{HCl}$ media, W303 $\alpha$ cells showed almost no viability, while $S$. boulardii cells were more than $70 \%$ viable (Figure 3). This confirms the findings of others who have shown that $S$. boulardii cells are more resistant to acidic conditions than their S. cerevisiae cousins [21].

To determine if the $S$. boulardii cells were undergoing PCD in the acidic environment, we repeated our cell death assays with cells cultured in $75 \mathrm{mM} \mathrm{HCl}(\mathrm{pH}$ 1.5), a scenario that mimics the conditions in the stomach [48]. DHR staining revealed that $92 \%$ of the $S$. boulardii cells cultured in an acidic environment contained ROS as compared to cells grown in rich YPD media (Figure 4A). FLICA staining also showed that $90 \%$ of the $S$. boulardii cells in the $\mathrm{HCl}$ solution, but only $1 \%$ of the control cell population had activated caspase-like activity (Figure 4B).

Finally, to better understand the mechanism of cell death at the molecular level, we generated microarray gene expression profiles of $S$. boulardii cells cultured in 

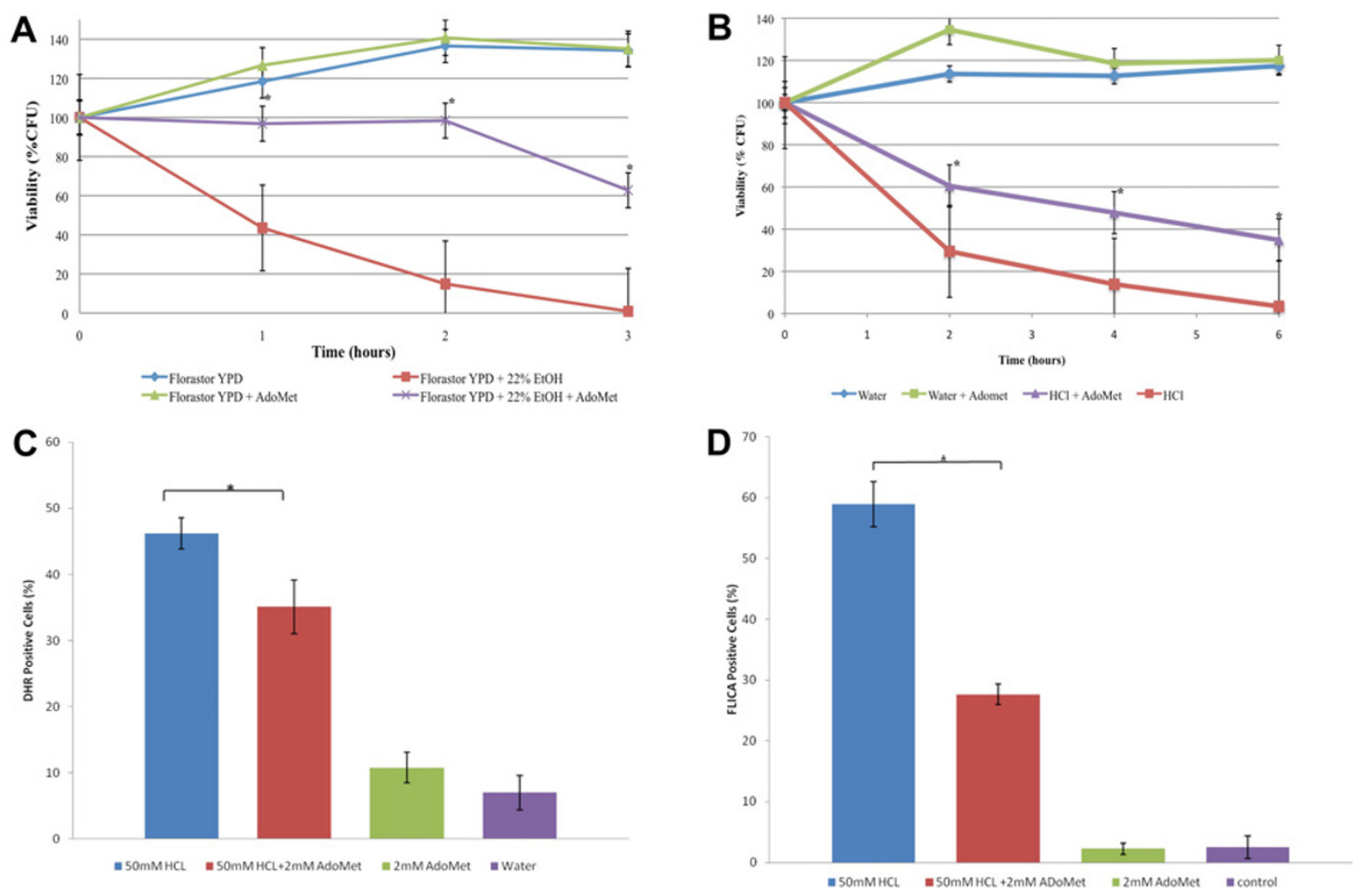

Figure 6 AdoMet protects S. boulardii from ethanol and HCI-Induced cell death. S. boulardii cells (Florastor) were cultured in rich YPD media overnight and resuspended in fresh media and allowed to reach exponential phase. (A) They were then resuspended in fresh media, in fresh media containing 22\% ethanol, in fresh media containing $1 \mathrm{mM}$ AdoMet, or in in fresh media containing 22\% ethanol and $1 \mathrm{mM}$ AdoMet and allowed to grow at $30^{\circ} \mathrm{C}$ for the indicated times. Viability was measured as percentage colony forming units. (B) Next, S. boulardii cells were resuspended in water, water containing $75 \mathrm{mM} \mathrm{HCl}$, water containing $75 \mathrm{mM} \mathrm{HCl}$ and $2 \mathrm{mM}$ AdoMet, or water containing 2 mM AdoMet alone. They were allowed to grow at room temperature for 1.5 hours. Viability was measured as percentage colony forming units. (C) Exponential phase S. boulardii cells were resuspended in the indicated culture conditions and allowed to grow at room temperature for 1.5 hr. Intracellular ROS accumulation was detected with $5 \mu \mathrm{g} / \mathrm{ml}$ of dihydrorhodamine 123. (D) Activated caspase-like enzymatic activity was detected after treatment using a FLICA apoptosis detection kit according to the manufacturer's specifications. At least three independent cultures were tested and compared. The differences were deemed statistically significant by the Student's t-test $(p<0.05)$.

an acidic environment. We found that a total of 947 genes were differentially expressed ( $\log 2$ values greater than 2 or less that -2 ) of which 470 were up-regulated and 457 down-regulated (Additional file 1). Significantly, functional annotation revealed that the upregulated genes were significantly $(\mathrm{p}<0.0005)$ overrepresented in cell death pathways (Figure 5; Table 1). One of these up-regulated cell death genes, RNY1, encodes a RNase T2 family member that is released from the vacuole into the cytosol during oxidative stress to promote yeast cell death [49]. Since the vacuole is the organelle most responsible for $\mathrm{pH}$ homeostasis in yeast [50], this may suggest that a similar mechanism of cell death may be occurring in S. boulardii cells cultured in an acidic environment. Finally, a significant majority of the other up-regulated cell death genes $(80 \%)$ were ORFs involved in mitochondrial function, including numerous genes encoding proteins involved in the electron transport chain (Table 1). These microarray results together with our characterization of the cell death phenotype described above suggest that $S$. boulardii cells undergo PCD when they are cultured in acidic conditions similar to those found in the stomach.

Previously published work has shown that S-adenosyl-Lmethionine (AdoMet) protects S. cerevisiae from programmed cell death [34]. To determine if AdoMet is also capable of rescuing $S$. boulardii from inducers that induce PCD, we first suspended S. boulardii cells either in $22 \%$ ethanol or in $22 \%$ ethanol containing $1 \mathrm{mM}$ AdoMet, for 3 hours. We discovered that both S. cerevisiae and S. boulardii cells cultured in ethanol containing AdoMet had higher viabilities than cells cultured in ethanol alone (Figure 6A). These results suggest that AdoMet is also capable of rescuing $S$. boulardii from programmed cell death.

Next, we wanted to determine if AdoMet could also rescue $S$. boulardii cells undergoing $\mathrm{HCl}$-induced 
programmed cell death. As shown in Figure 6B, the viability of Florastor cells cultured in an acidic environment was significantly enhanced in the presence of $2 \mathrm{mM}$ AdoMet. Next, we showed that $2 \mathrm{mM}$ AdoMet decreased both ROS generation (Figure 6C) and caspase activation (Figure 6D) in $S$. boulardii cells cultured in 50 $\mathrm{mM} \mathrm{HCl}$ suggesting that this supplement may enhance cell viability by preventing programmed cell death.

\section{Conclusions}

Our study provides evidence that suggests that $S$. boulardii cells undergo programmed cell death in response to stimuli known to induce PCD in S. cerevisiae, including an acidic environment. Significantly, we were also able to show that the addition of AdoMet is able to decrease caspase activity and ROS production while increasing viability in $S$. boulardii cells treated with hydrochloric acid. Clinically, these results suggest that taking AdoMet - a commercially available and FDA approved dietary supplement - with S. boulardii could be useful in increasing the viability of the yeast during its passage through the acidic environment of the stomach. This should improve its effectiveness both as a probiotic and as a treatment for diarrhea.

\section{Additional file}

Additional file 1: Differentially Regulated Genes in S. boulardii Cells
Cultured in an Acidic Environment. S. boulardii genes showing 4-fold
or greater increase (up-regulated) or decrease (down-regulated)
expression in response to an acidic environment. This data has been
submitted to the Gene Expression Omnibus (GEO) at the NCBI with
accession number, GSE43271.

\section{Competing interests}

The authors declare no competing interests.

\section{Authors' contributions}

VC, DG, and KM contributed equally to this paper. Their names are listed in alphabetical order. DL, DG, KM, MH, VC and NA designed, performed, and analyzed the experiments. VC, DL, and NA. wrote the manuscript. All authors read and approved the final manuscript.

\section{Acknowledgments}

Our laboratory is supported by the following grants awarded to N. Austriaco: NIGMS R15 GM094712, NSF MRI-R2 0959354, NIH Grant 8 P20 GM103430-12 to the Rhode Island INBRE Program for student training, and a CAFR faculty research grant from Providence College. The funders had no role in study design, data collection and analysis, decision to publish, or preparation of the manuscript. Non nisi te, Domine.

\section{Author details}

'Department of Biology, Providence College, 1 Cunningham Square, Providence, Rhode Island 02918, USA. ${ }^{2}$ Present Address: Massachusetts General Hospital, 149 13th St., Rm. 6133, Charlestown, MA 02129, USA. ${ }^{3}$ Present Address: Boston University School of Medicine, 72 E Concord St, Boston, MA 02118, USA. ${ }^{4}$ Present Address: Tufts University, Miner Hall 222, Medford, MA 02155, USA.

Received: 27 August 2012 Accepted: 5 February 2013

Published: 13 February 2013

\section{References}

1. FAO/WHO: Guidelines for the Evaluation of Probitics in Food. Food and Agriculture Organization of the United Nations: In. London Ontario, Canada: World Health Organization; 2002.

2. Gismondo MR, Drago L, Lombardi A: Review of probiotics available to modify gastrointestinal flora. Int J Antimicrob Agents 1999, 12(4):287-292.

3. McCullough MJ, Clemons KV, McCusker JH, Stevens DA: Species identification and virulence attributes of Saccharomyces boulardii (nom. inval.). J Clin Microbiol 1998, 36(9):2613-2617.

4. Htwe K, Yee KS, Tin M, Vandenplas Y: Effect of Saccharomyces boulardii in the treatment of acute watery diarrhea in Myanmar children: a randomized controlled study. Am J Trop Med Hyg 2008, 78(2):214-216.

5. McFarland LV: Meta-analysis of probiotics for the prevention of traveler's diarrhea. Travel Med Infect Dis 2007, 5(2):97-105.

6. Brassart DSE: The use of probiotics to reinforce mucosal defense mechanisms. Trends Food Sci Technol 1997, 8:321-326.

7. Surawicz CM, McFarland LV, Greenberg RN, Rubin M, Fekety R, Mulligan ME, Garcia RJ, Brandmarker S, Bowen K, Borjal D, et al: The search for a better treatment for recurrent Clostridium difficile disease: use of high-dose vancomycin combined with Saccharomyces boulardii. Clin Infect Dis 2000, 31(4):1012-1017.

8. Tung JM, Dolovich LR, Lee CH: Prevention of Clostridium difficile infection with Saccharomyces boulardii: a systematic review. Can J Gastroenterol 2009, 23(12):817-821.

9. Dinleyici EC, Eren M, Ozen M, Yargic ZA, Vandenplas Y: Effectiveness and safety of Saccharomyces boulardii for acute infectious diarrhea. Expert Opin Biol Ther 2012, 12(4):395-410.

10. Sudha MR, Bhonagiri S, Kumar MA: Oral consumption of potential probiotic Saccharomyces boulardii strain Unique 28 in patients with acute diarrhoea: a clinical report. Benef Microbes 2012, 3(2):145-150.

11. Pozzoni P, Riva A, Bellatorre AG, Amigoni M, Redaelli E, Ronchetti A, Stefani $\mathrm{M}$, Tironi R, Molteni EE, Conte D, et al: Saccharomyces boulardii for the prevention of antibiotic-associated diarrhea in adult hospitalized patients: a single-center, randomized, double-blind, placebo-controlled trial. Am J Gastroenterol 2012, 107(6):922-931.

12. MCFarland LV: Systematic review and meta-analysis of Saccharomyces boulardii in adult patients. World J Gastroenterol 2010, 16(18):2202-2222.

13. Vandenplas $Y$, Brunser $O$, Szajewska H: Saccharomyces boulardii in childhood. Eur J Pediatr 2009, 168(3):253-265.

14. Correa NB, Penna FJ, Lima FM, Nicoli JR, Filho LA: Treatment of acute diarrhea with Saccharomyces boulardii in infants. J Pediatr Gastroenterol Nutr 2011, 53(5):497-501.

15. Kelesidis T, Pothoulakis C: Efficacy and safety of the probiotic Saccharomyces boulardii for the prevention and therapy of gastrointestinal disorders. Therap Adv Gastroenterol 2012, 5(2):111-125.

16. Zanello G, Meurens F, Berri M, Salmon H: Saccharomyces boulardii effects on gastrointestinal diseases. Curr Issues Mol Biol 2009, 11(1):47-58.

17. Canonici A, Siret C, Pellegrino E, Pontier-Bres R, Pouyet L, Montero MP, Colin C, Czerucka D, Rigot V, Andre F: Saccharomyces boulardii improves intestinal cell restitution through activation of the alpha2beta1 integrin collagen receptor. PLoS One 2011, 6(3):e18427.

18. Pothoulakis C: Review article: anti-inflammatory mechanisms of action of Saccharomyces boulardii. Aliment Pharmacol Ther 2009, 30(8):826-833.

19. Edwards-Ingram LC, Gent ME, Hoyle DC, Hayes A, Stateva LI, Oliver SG: Comparative genomic hybridization provides new insights into the molecular taxonomy of the Saccharomyces sensu stricto complex. Genome Res 2004, 14(6):1043-1051.

20. Mitterdorfer G, Mayer HK, Kneifel W, Viernstein H: Clustering of Saccharomyces boulardii strains within the species $S$. cerevisiae using molecular typing techniques. J Appl Microbio/ 2002, 93(4):521-530.

21. Edwards-Ingram L, Gitsham P, Burton N, Warhurst G, Clarke I, Hoyle D, Oliver SG, Stateva L: Genotypic and physiological characterization of Saccharomyces boulardii, the probiotic strain of Saccharomyces cerevisiae. Appl Environ Microbiol 2007, 73(8):2458-2467.

22. Fietto JL, Araujo RS, Valadao FN, Fietto LG, Brandao RL, Neves MJ, Gomes FC, Nicoli JR, Castro IM: Molecular and physiological comparisons between Saccharomyces cerevisiae and Saccharomyces boulardii. Can J Microbiol 2004, 50(8):615-621.

23. Graff S, Chaumeil JC, Boy P, Lai-Kuen R, Charrueau C: Influence of pH conditions on the viability of Saccharomyces boulardii yeast. J Gen Appl Microbiol 2008, 54(4):221-227. 
24. Pecquet S, Guillaumin D, Tancrede C, Andremont A: Kinetics of Saccharomyces cerevisiae elimination from the intestines of human volunteers and effect of this yeast on resistance to microbial colonization in gnotobiotic mice. Appl Environ Microbiol 1991, 57(10):3049-3051.

25. Rodrigues AC, Cara DC, Fretez SH, Cunha FQ, Vieira EC, Nicoli JR, Vieira LQ: Saccharomyces boulardii stimulates slgA production and the phagocytic system of gnotobiotic mice. J Appl Microbiol 2000, 89(3):404-414.

26. Czerucka D, Piche T, Rampal P: Review article: yeast as probiotics Saccharomyces boulardii. Aliment Pharmacol Ther 2007, 26(6):767-778.

27. Blehaut H, Massot J, Elmer GW, Levy RH: Disposition kinetics of Saccharomyces boulardii in man and rat. Biopharm Drug Dispos 1989, 10(4):353-364.

28. Boddy AV, Elmer GW, McFarland LV, Levy RH: Influence of antibiotics on the recovery and kinetics of Saccharomyces boulardii in rats. Pharm Res 1991, 8(6):796-800

29. Graff S, Chaumeil JC, Boy P, Lai-Kuen R, Charrueau C: Formulations for protecting the probiotic Saccharomyces boulardii from degradation in acidic condition. Biol Pharm Bull 2008, 31(2):266-272.

30. Madeo F, Frohlich E, Frohlich KU: A yeast mutant showing diagnostic markers of early and late apoptosis. J Cell Biol 1997, 139(3):729-734.

31. Liang Q, Li W, Zhou B: Caspase-independent apoptosis in yeast. Biochim Biophys Acta 2008, 1783(7):1311-1319.

32. Mazzoni C, Falcone C: Caspase-dependent apoptosis in yeast. Biochim Biophys Acta 2008, 1783(7):1320-1327.

33. Kitagaki $H$, Araki $Y$, Funato $K$, Shimoi $H$ : Ethanol-induced death in yeast exhibits features of apoptosis mediated by mitochondrial fission pathway. FEBS Lett 2007, 581(16):2935-2942.

34. Malakar D, Dey A, Basu A, Ghosh AK: Antiapoptotic role of S-adenosyl-Imethionine against hydrochloric acid induced cell death in Saccharomyces cerevisiae. Biochim Biophys Acta 2008, 1780(7-8):937-947.

35. Carmona-Gutierrez D, Ruckenstuhl C, Bauer MA, Eisenberg T, Buttner S, Madeo F: Cell death in yeast: growing applications of a dying buddy. Cell Death Differ 2010, 17(5):733-734.

36. Rockenfeller P, Madeo F: Apoptotic death of ageing yeast. Exp Geronto 2008, 43(10):876-881.

37. Herker $\mathrm{E}$, Jungwirth $\mathrm{H}$, Lehmann KA, Maldener C, Frohlich KU, Wissing $\mathrm{S}$, Buttner S, Fehr M, Sigrist S, Madeo F: Chronological aging leads to apoptosis in yeast. J Cell Biol 2004, 164(4):501-507.

38. Severin FF, Hyman AA: Pheromone induces programmed cell death in $\mathrm{S}$. cerevisiae. Curr Biol 2002, 12(7):233-235.

39. Zhang NN, Dudgeon DD, Paliwal S, Levchenko A, Grote E, Cunningham KW: Multiple signaling pathways regulate yeast cell death during the response to mating pheromones. Mol Biol Cell 2006, 17(8):3409-3422.

40. Frohlich KU, Fussi H, Ruckenstuhl C: Yeast apoptosis-from genes to pathways. Semin Cancer Biol 2007, 17(2):112-121.

41. Amberg DC BD, Strathern JN: Methods in Yeast Genetics: A Cold Spring Harbor Laboratory Manual. Cold Spring Harbor, NY: In: Cold Spring Harbor Laboratory Press; 2005

42. Phillips AJ, Sudbery I, Ramsdale M: Apoptosis induced by environmental stresses and amphotericin B in Candida albicans. Proc Natl Acad Sci U S A 2003, 100(24):14327-14332.

43. Bryan R: Quantitate apoptosis in yeast using SR FLICA. LLC: Immunochemistry Technologies; 2005.

44. Shirtliff ME, Krom BP, Meijering RA, Peters BM, Zhu J, Scheper MA, Harris ML, Jabra-Rizk MA: Farnesol-induced apoptosis in Candida albicans. Antimicrob Agents Chemother 2009, 53(6):2392-2401.

45. Eisen MB, Spellman PT, Brown PO, Botstein D: Cluster analysis and display of genome-wide expression patterns. Proc Natl Acad Sci U S A 1998, 95(25):14863-14868.

46. Giannattasio S, Guaragnella N, Corte-Real M, Passarella S, Marra E: Acid stress adaptation protects Saccharomyces cerevisiae from acetic acidinduced programmed cell death. Gene 2005, 354:93-98.

47. Ludovico P, Sousa MJ, Silva MT, Leao C, Corte-Real M: Saccharomyces cerevisiae commits to a programmed cell death process in response to acetic acid. Microbiology 2001, 147(Pt 9):2409-2415.

48. Barlow AP, Hinder RA, DeMeester TR, Fuchs K: Twenty-four-hour gastric luminal $\mathrm{pH}$ in normal subjects: influence of probe position, food, posture, and duodenogastric reflux. Am J Gastroenterol 1994, 89(11):2006-2010
49. Thompson DM, Parker R: The RNase Rny1p cleaves tRNAs and promotes cell death during oxidative stress in Saccharomyces cerevisiae. J Cell Biol 2009, 185(1):43-50.

50. Brett CL, Kallay L, Hua Z, Green R, Chyou A, Zhang Y, Graham TR, Donowitz M, Rao R: Genome-wide analysis reveals the vacuolar $\mathrm{pH}$-stat of Saccharomyces cerevisiae. PLoS One 2011, 6(3):e17619.

doi:10.1186/1471-2180-13-35

Cite this article as: Cascio et al:: S-Adenosyl-L-Methionine protects the probiotic yeast, Saccharomyces boulardii, from acid-induced cell death. BMC Microbiology 2013 13:35.

\section{Submit your next manuscript to BioMed Central and take full advantage of:}

- Convenient online submission

- Thorough peer review

- No space constraints or color figure charges

- Immediate publication on acceptance

- Inclusion in PubMed, CAS, Scopus and Google Scholar

- Research which is freely available for redistribution

Submit your manuscript at www.biomedcentral.com/submit
C) BioWed Central 